\title{
Strategies for dealing with resistance to recommendations from accident investigations
}

Jonas Lundberg, Carl Rollenhagen, Erik Hollnagel and Amy Rankin

\section{Linköping University Post Print}

N.B.: When citing this work, cite the original article.

Original Publication:

Jonas Lundberg, Carl Rollenhagen, Erik Hollnagel and Amy Rankin, Strategies for dealing with resistance to recommendations from accident investigations, 2012, Accident Analysis and Prevention, (45), 455-467.

http://dx.doi.org/10.1016/j.aap.2011.08.014

Copyright: Elsevier

http://www.elsevier.com/

Postprint available at: Linköping University Electronic Press

http://urn.kb.se/resolve?urn=urn:nbn:se:liu:diva-76190 


\title{
Strategies for dealing with resistance to recommendations from accident investigations
}

\author{
Corresponding author: Jonas Lundberg
}

Linköping University, Department of Science and Technology, Campus Norrköping, 60174 Norrköping, Sweden

Jonas.lundberg@liu.se

Phone: +46 (0) 11363452

Fax: +46(0) 11363270

Carl Rollenhagen

KTH

Royal Institute of Technology, Department of Philosophy and Vattenfall Power Consultant AB, Box 527, SE-162 16 Stockholm, Sweden

Phone: + $46(0) 85397260$

Carl.rollenhagen@vattenfall.com

\author{
Erik Hollnagel \\ University of Southern Denmark \\ Institute of Public Health \\ DK-5000 Odense C, Denmark \\ hollnagel.erik@gmail.com
}

Amy Rankin

Linköping University, Department of Computer and Information Science, 58183 Linköping, Sweden

amyra@ida.liu.se

Abstract. Accident investigation reports usually lead to a set of recommendations for change. These recommendations are, however, sometimes resisted for reasons such as various aspects of ethics and power. When accident investigators are aware of this, they use several strategies to overcome the resistance. This paper describes strategies for dealing with four different types of resistance to change. The strategies were derived from qualitative analysis of 25 interviews with Swedish accident investigators from seven application domains. The main contribution of the paper is a better understanding of effective strategies for achieving change associated with accident investigation. 
Keywords: accident investigation, remedial actions, safety culture

\section{Introduction}

Accident investigation methods and practices is a classical and well-researched subject in safety science. Many different methods and models (Heinrich, 1934; Gordon, 1949; Lehto and Salvendy, 1991; Svenson, 1991; Knox and Eicher, 1992; Kjellén, 2000; O'Hare, 2000) have been suggested to support efficient accident investigation and new methods and models continue to emerge (see Hollnagel, 2004; Factor et al., 2007; Santos-Reyes and Beard, 2009). A main focus of current investigation methods is understanding why accidents occur, and on how to provide feedback to decision makers about the causes of negative events. Reflecting this situation, Swedish accident investigation manuals and investigation policy documents focus mainly on activities related to identifying causes and reporting them (Lundberg et al., 2009). In a recent report sampling 108 Swedish accident investigators, Rollenhagen et al. (2010) found the same tendency in self-reports on what kind of activities they spend the most time on.

Reflecting that accident investigations are often seen as rational processes of discovering causes, and then fixing the most important ones, there are aspects of accident investigation that have received less interest than data collection and analysis. There has in particular been comparatively little research on the later stages of the accident investigation process where recommendations are formulated, communicated, implemented and assessed for their efficiency. For instance, documents meant to guide accident investigation in several domains in Sweden did not present much receive much guidance on how to go from analysis to recommendations (Lundberg et al., 2009). Rollenhagen et al. (2010) found that little time and effort were invested in suggesting recommendations relative to the time spent in data collection and analysis. An implicit assumption is thus that having identified and reported the causes, the work is basically done. Assuming that if only the causes can be found, then accidents can be prevented, then it would be reasonable to focus efforts on better analysis methods. However, other issues than weak analysis methods can derail investigations (Elvik, 2010; Lundberg et al., 2010) during all phases, even before having started. For instance, investigation resources, such as money or staff, can be lacking so that some kinds of investigations cannot be done. Moreover, some previous research suggests that important work remains after having identified causes. A particular finding, important to the theme of this study, was that accident investigators tended to adjust their investigation efforts, such as data collection, analysis, and design of remedial actions, to what they perceived to be "preventable causes". That is, adjustments to what they perceived as possible to achieve rather than strictly what were the most critical factors identified (Lundberg et al., 2010). Moreover, a study of decision making in power plant has also highlighted that managers can select from the causes, rather than implement them all, and that top manager attention can be needed to get changes implemented (Carroll, 2006). Nevertheless, there is little research on what investigators actually do to get their recommendations implemented.

The present study looks at the subset of accident investigation activities that focus on designing recommendations and achieving change rather than on identification of and 
understanding of causes. In particular, we focus on how accident investigators cope with resistance to change. Research on organizational change and resistance to change is a well-researched subject in organizational theory and practice (Coch and French, 1948; Tichy, 1983; Ashforth and Lee, 1990; Lau and Woodman, 1995; Judge et al., 1999; Piderit, 2000; Wanberg and Banas, 2000). Research in safety of organizational change has focused on issues such as resistance to organizational change as a cause for accidents (Tveiten et al., 2006) and how to manage safety during change (Grote, 2008; Herrera et al., 2009). However, how accident investigators in particular cope with resistance to change is a less explored topic.

Firstly, we wish to highlight that investigators do cope with resistance to change, and that it affects their recommendations. The recommendations do not simply follow from the causes found in the analysis. More importantly, we describe how they seek to adapt their recommendations to the receiving organization to ensure that the recommendations will have a desired effect on safety. Such practices are basically 'rules of thumb' that have emerged from experience, together with more or less articulated beliefs about the nature of good recommendation relative to recipient characteristics.

The strategies for coping with resistance to change that emerged from a qualitative study based on interviews with experienced accident investigators are the main contribution of this article. Three theoretical frameworks are used to discuss the findings: organizational change and resistance to change, resilience engineering, and safety culture. The strategies for achieving change are characterized in terms of how they appeal to ethics aspects of the safety culture as well more broadly how they rely on power relations. The strategies for being resilient (achieving change despite resistance), are also discussed in relation of forces of resistance to organizational change.

In section 1 the theoretical frameworks are briefly described. Section 2 present the methods used for data collection and analysis and section 3 presents the results. Section 4 discusses the findings and section 5 presents general conclusions. Note that the central stakeholders described in this report could be accident investigators themselves as well as other actors involved in suggesting, implementing and following up recommendations.

\subsection{Resistance to change}

Organizational change and resistance to change is a topic in management and organisatifonal theory that has received much interest (Coch and French, 1948; Tichy, 1983; Ashforth and Lee, 1990; Lau and Woodman, 1995; Judge et al., 1999; Piderit, 2000; Wanberg and Banas, 2000). Studies have focused on driving and restraining forces of change (Lewin, 1947), which relates to resilience (see below). Studies have also focused on context factors such as being informed and participation in change (Cooper, 1998; Wanberg and Banas, 2000), on individual recipient characteristics such as selfesteen, and on managerial dispositional traits (Judge et al., 1999). Moreover, organizational change has been analyzed in terms of "issue-selling" (Dutton and Ashford, 1993; Dutton et al., 1997). However, accident investigators do not always end up with wicked problems, and have very limited choice in the timing of presentation of their recommendations. Nevertheless, accident investigators might also be "reading the 
wind", to assess to what extent organizational conditions for receiving the recommendations will be favorable, and what conditions to frame their recommendations towards.

Of particular relevance here are issues regarding changes that aim for enhanced safety. One aspect that distinguishes safety related change from other changes is the difficulty in validating the results. Measuring safety is generally considered a very difficult task, at least compared with many other aspects of measuring the results of changes in organizations (Lofquist et al., 2011).

A second aspect of safety related changes, which is particularly interesting in view of current perspectives of organizational change, has to do with the view that resistance to change might be a positive feature of organizational change (Jansen 2000). For instance, the various discussions that may emerge as a consequence of change efforts can be a positive force leading to less groupthink and more productive and innovative ideas (Mabin et al., 2001). Change itself can be a threat or even a cause for accidents (Tveiten et al., 2006), whether it comes from suggested remedial actions or not, and resistance can thus be a positive force.

Considering that safety is given high priority in many organizations and that change may be associated with risks, then it is particularly important that change suggestions are subject to thorough validation. The often-noted "natural" resistance to change in many organizations might therefore be an important asset in safety related change projects, at least if used correctly.

A third factor, which is important for the present discussion concerns various suggestions about type of changes perceived in a dimension of incremental change towards radical innovative change. For example, Paulino (2009) has discussed types of changes suitable for High Reliable Organizations (HROs) and has suggested a framework that combines the adaption and selection perspectives on change management. In the adaptation perspective, change is perceived as beneficial for survival whereas in the selection perspective, it is inertia that is perceived as beneficial. According to (Paulino, 2009), in HROs there are well-tested and proven ways of approaching situations that favors inertia, since change may threaten accountability. In less reliable organizations, with lesser demands for accountability and less well-proven ways of acting, change is instead necessary to cope with various threat situations. Rather than adhering to one or the other of these perspectives on organizational change, we assume that these two perspectives are complementary. This is in line with some other researchers (Singh et al., 1986; Carroll and Teo, 1996; Dent and Galloway Goldberg, 1999; Schwarz and Shulman, 2007; Paulino, 2009). These aspects work both for and against change management: some change might be negative for safety because new solutions might be associated with high uncertainty. However, depending on the weaknesses found in an evaluation of safety, the consequences of not attending to needs for safety related change might be catastrophic, and such awareness can work in favor for safety related change - as well as innovative changes. On the other hand, the difficulties associated with measuring outcomes of safety related changes can work against safety related changes. 
The concept of resistance to change may itself create a positive connotation in a safety context because such resistance might be used to elaborate safety discussions -to test and criticize various alternatives. Taken together these theoretical perspectives on change and resistance to change can all be used stimulate discussions and lead to new research topics in event investigation theory and practices.

\subsection{Resilience}

Although much of the research regarding organizational change has focused on the relations between managers and individual workers and on resistance in the individual (Dent and Galloway Goldberg, 1999) other perspectives also have a long tradition (Lewin, 1947). In the force-field theory (Lewin, 1947), driving forces (e.g. management pressure for productivity) meet restraining forces (such as hostility), resulting in productivity at a point of equilibrium. Change is achieved through starting a movement, by unfreezing, and then re-freezing it at a new point. The underlying view is that forcefield theory is in some way similar to resilience, which has recently gained in popularity in safety research (e.g. Lundberg and Johansson, 2006). Resilience focuses on achieving beneficial change. Resilience in safety research borrows from Ecology, where resilience is seen as the ability to respond to changing circumstances by moving from one point of rest (stability) to another. The circumstances are seen as forces that attract the system to a point of stability (a dynamically stable region), or move it towards some other point in response to changing circumstances, or force it into extinction. A resilient system adapts by changing its state in a way that is beneficial for the survival of the system (Holling, 1973). However, the 'forces' mentioned in research on ecological systems are only loosely related to safety in human activities. In this study, we focus on how aspects of the organizational culture can act as 'forces' that may resist change, an approach that has previously been used to describe restraining and driving forces of safety culture (Cooper, 1998). This recognizes a crucial difference between ecological and sociotechnical systems, namely that the former respond passively to forces of change, while the latter respond actively. This means that they may have an explicit goal or objective (in other words, an intention) that determines how they respond to various influences, in particular 'pressures' to change. Ecological systems do not do so. Indeed, a resilient system may even respond to the expectation that something is going to happen.

Resilient systems are able to respond, monitor, learn, and adapt prior to, during, or after expected or unexpected events (Hollnagel, 2009).

Accident investigators can consequently be seen as agents of resilience: as they find out how the accident occurred, they can use this to contribute to improve the organizations' abilities to respond and monitor. Yet in order to bring about this end result, investigators may have to use various strategies, or rules of thumb, to overcome a possible resistance to change.

\subsection{Safety Culture}

In safety research, the two constructs of safety culture and safety climate are usually perceived as important forces driving safe (or unsafe) behaviors and practices. The concept of safety culture was introduced after the Chernobyl accident in 1986, and has had a strong impact on organisational safety research and practice ever since. There is 
however no consensus on how to define safety culture and safety climate, although, beliefs, attitudes, values and perceptions about various safety related state of affairs usually are included. Attitudes and values (e.g. towards safety) is often seen as aspects of the cultural construct, and perceptions (e.g. the current level of risk) are often seen as belonging to climate (Guldenmund, 2000). Comprehensive overviews of safety culture can be found in (Guldenmund, 2000; Choudhry et al., 2007) and shall therefore not be repeated here. Instead we draw attention to two issues that are glaringly absent in current safety culture research but which we consider highly relevant for strategies to overcome resistance to change.

The first issue is the limited role and use of ethics in the current safety discourse. For example, an aspect of ethics that is of high relevance for the present discussion is how people approach rules and recommendations about what they ought to do. Although ethics is not completely missing in safety culture discussions, it is usually not addressed explicitly. Two illustrative examples are the common agreement that management commitment to safety is a hallmark of a good safety culture and that a good safety culture should be a 'just culture.' A discussion of these topics should rightly be seen as part of the realm of ethics.

One example of how researchers explicitly discuss ethical concerns associated with risk and safety is described in Hansson's (2007). He proposes three characteristic patterns in a discussion about ethics and risk:

- $\quad$ Appealing to duty - corresponding to a 'fence' or barrier (e.g. deontology or rule ethics). Enforcing recommendations by regulations is supported by a rule ethical approach (rules should be followed).

- $\quad$ Trading-off - corresponding to the metaphor of a 'balance' (e.g. utilitarianism). In cases where there are no rules, the arguments for implementing recommendations can be supported by, for instance, by pointing to various types of consequence.

- $\quad$ Orienting - corresponding to a 'compass' (virtue ethics). A recommendation can be supported by arguing that it is morally justified to adhere to apply a precautionary principle and that actors in certain risk domain should exhibit personal characteristics associated with this principle.

A second neglected aspect of safety culture is the issue of power. It has recently received some attention through a thorough review of power versus safety (e.g. Antonsen, 2009). This issue is of relevance here, since power determines whether a stakeholder can expect to get their decisions implemented. Stakeholders in an organization differ with regard to how much power they have. Depending on the distribution of power, some stakeholders may have a disproportionately small influence on whether recommendations should be implemented or not. This observation might seem obvious and trivial but that does not undermine its relevance in the present context. Although we do not provide an in-depth analysis of power relations, we will highlight how strategies to overcome resistance draw heavily on the power to enforce recommendations on an (potentially) unwilling recipient. This corresponds to the first of three dimensions proposed by Antonsen (2009). We also discuss the second dimension, that of setting the 
agenda, and the third dimension, that of imposing values on others.

\subsection{Framework summary}

In summary, we view resistance to change in terms of such forces as economy or safety priorities. Viewing change in terms of forces has been adopted for a long time in organizational theory (Lewin, 1947) and safety (Rasmussen, 1997; Cooper, 1998). This includes temporary or even momentary shifts of the system due to performance shaping factors (Hollnagel, 2004). For recipient organizations, resistance is not a purely negative force, but might be necessary for the survival of the organization in view of its current situation with competitors, and other constraints that restrict what an organization can do. Resistance may limit what can be achieved through accident investigation and the recommendations that follow. The force field view builds on the same basic ideas as resilience, i.e. the ability to adapt to events and circumstances. Investigators, as agents of resilience, have to deal with resistance in some way, through strategies or rules-ofthumb, to get the most out of their investigation effort. Those strategies depend on the culture of the recipient, in particular on recipient ethics regarding how they approach rules and recommendations, as well as on power relations between stakeholders.

In our study, we analyze

- $\quad$ The kinds of resistance to change that the investigators talk about.

- $\quad$ Strategies or rules-of-thumb for overcoming resistance to change that investigators talk about.

- How the strategies relate to ethics (fence, balance, compass) regarding how recipients approach recommendations, and more broadly how they relate to three power relations between stakeholders.

\section{Method}

The data collection method has been described in detail in previous publications (Korolija and Lundberg, 2010; Lundberg et al., 2010). The following description provides an overview, and focuses on additions to that data set from the earlier study used by the analysis conducted in this paper.

\subsection{Interviews}

Twenty-two semi-structured interviews were conducted during 2007. These were supplemented by three new interviews in the aviation domain (air traffic control) during 2010 (see Table 1), which were not used in the two previous studies. In-house investigators, e,g, in patient safety, mainly addressed their own organizations, whereas investigators in the maritime domain addressed other stakeholders. The distinction is not clear-cut however, since causes in an in-house investigation may extend to the outside just as an investigator in an independent authority may have to address factors having to do with their own practices.

Informants were recruited based on a list of contacts provided by the Swedish Civil Contingencies Agency, and through contact with the authorities. The purpose of the study was to collect experiences of accident investigation from investigators active in various domains in Sweden, and to publish the experiences in reports and scientific publications. This was also explained to all participants. Due to this reason the 
informants were spread over as many domains as was practically possible, rather than focused on one domain only.

\begin{tabular}{ll|l|l|l|l}
\hline $\mathbf{N}$ & Excerpts & Domain & N & Excerpts & Domain \\
\hline 3 & $3 / 2 / 2$ & Rail & 3 & $3 / 3 / 2$ & Nuclear \\
\hline 3 & $5 / 4 / 2$ & Maritime & $6(5)$ & $5 / 4 / 4 / 3 / 2$ & Patient safety \\
\hline 4 & $7 / 4 / 3 / 2$ & Road & 3 & $5 / 2 / 2$ & $\begin{array}{l}\text { Aviation } \\
\text { (air traffic control) }\end{array}$ \\
\hline 3 & $6 / 6 / 1$ & Work, general & & & .
\end{tabular}

Table 1: Informants and excerpts. $\mathrm{N}=$ number of informants (a number in parentheisis indicates that fewer informats than the total number interviewed contributed to the data set used here), Excerpts=number of excerpts used from each domain and informant.

An interview manual was developed based on previous research in the area of accident investigation (Korolija and Lundberg, 2010) and then and pilot tested. Questions 25 to 2.7c, and question 4.15a, in Table 2 (see Appendix, Lundberg et al. 2010 for the complete interview guide) specifically focused on change and resistance to change. The whole interview manual covered 1) background information about the investigators 2) the phases of an investigation 3) professional investigation manuals 4) accident models 5) safety culture.

2.5. Can you give a little more detailed description of how you work when specifying measures?

2.6. Do you usually estimate the efficiency of various measures? If so, how?

2.7. How should measures be formulated?

2.7.a. How important is it that the addressed organization accepts the proposed measures?

2.7.b. How do you work with addressed organizations' acceptance of measures?

2.7.c. How do you work with the adjustment cost-benefit? How is this adjustment assessed?

4.15.a. Is it possible to somehow adjust measures to safety levels?

Table 2: Interview questions directly addressing change and resistance to change.

Due to the open nature of the interviews, informants sometimes talked about resistance to change even when queried about something else. An analysis of the entire material was therefore made to capture such statements.

\subsection{Analysis}

Our results were first analyzed using a qualitative bottom up-approach following Miles and Huberman (1994). The safety culture features and strategies for dealing with them that emerged from the data are presented in the results section (see Table 3). The strategies for overcoming resistance to change were finally analyzed in a top-down fashion, using our analytical framework, in terms of ethics (the compass, scales, and fence) and power. This analysis is presented in the discussion section (see Table 4).

The interviews were broken down to excerpts that were entered into a database (Bookends for Mac), resulting in a collection of more than 800 excerpts. In the first analysis of the excerpts, anything that had to do with changing the level of safety was 
included. Core statements were written, in order to summarize each excerpt by a single sentence. Re-reading the core statements, and the excerpts, revealed that a common theme in many cases was about difficulties and strategies for achieving change, that is to get recommendations accepted and implemented by the recipient.

During the second analysis round, the main theme was resistance to change. Other aspects of safety degradation or increased safety were excluded. This resulted in 82 excerpts being used for the analysis (see Table 1 for a description of excerpts used per domain and informant). The excerpts contain views and recollections about safety work, often in the form of short descriptions of situations that the informants had experienced.

Although some statements only described different kinds of resistance to change, many statements also described what the accident investigators did to overcome resistance to change. Grouping the statements together resulted in four overarching themes exemplifying safety culture characteristics (presented in the first part of the results section). The core statements were entered under these headings into a document in the Mellel word processor, in which links can be made in the text to the excepts in the Bookends database. This corresponds to a hypertext "code card" (Miles and Huberman, 1994). Each card representing an overarching theme was also broken down into subcards by grouping similar core statements together, and giving them a heading. This resulted in the strategies for overcoming resistance to change presented in the second part of the results section.

After grouping the excerpts into themes, the excerpts in each section were re -read to select excerpts to illustrate and exemplify the data material in the text below. Excerpts were selected from all the seven domains. It should be noted that the categories are not mutually exclusive. For instance, a culture that does not have safety as a top priority may also be a resource weak culture. During the analysis, the hypertext connections to specific excerpts were kept. In this paper however, specific references have been replaced with general references to domains, e.g. (road), except in sensitive cases where they have been made anonymous.

\section{Results}

Numerous reasons for safety degradation and reduced effectiveness of recommendations were mentioned during the interviews. Among those, resistance to change emerged as an important central theme. The different sources of resistance were not by themselves surprising (Table 3, columns 1 and 2). More interestingly, the investigators explained what they did to overcome resistance to change (Table 3 , column 3). We describe those strategies, or rules-of-thumb, below.

Note that the domains in which the analysis is grounded is written in the text or noted in parenthesis, e.g. (work). The excerpts were translated from Swedish by the first author.

\begin{tabular}{l|l|l}
\hline Safety culture feature & Resistance to change & $\begin{array}{l}\text { Strategy for overcoming resistance to } \\
\text { change }\end{array}$ \\
\hline Cultures with & Resisting demands backed & Back up by law \\
\hline
\end{tabular}




\begin{tabular}{|c|c|c|}
\hline $\begin{array}{l}\text { institutionalized minimum } \\
\text { safety standards }\end{array}$ & $\begin{array}{l}\text { up by law, when the } \\
\text { enforcement of demands is } \\
\text { not monitored. } \\
\text { (see section 3.2.1) }\end{array}$ & Suggesting change \\
\hline \multirow[t]{7}{*}{ Resource-weak cultures } & \multirow{7}{*}{$\begin{array}{l}\text { Lack of money stops } \\
\text { remedial actions. } \\
\text { Cost-benefit depends on } \\
\text { the safety climate. } \\
\text { (see also section } 3.2 .1 \text { ) }\end{array}$} & $\begin{array}{l}\text { Demand that remedial actions are } \\
\text { implemented regardless of cost. }\end{array}$ \\
\hline & & $\begin{array}{l}\text { Leave the cost-benefit decision to the law } \\
\text { makers. }\end{array}$ \\
\hline & & $\begin{array}{l}\text { Recommendations that are known to be too } \\
\text { expensive and are expected to be turned } \\
\text { down by the recipient are nevertheless } \\
\text { proposed. }\end{array}$ \\
\hline & & $\begin{array}{l}\text { Give recommendations regardless of cost and } \\
\text { leave the decision entirely to the recipient. }\end{array}$ \\
\hline & & Set a price tag on recommendations. \\
\hline & & Propose alternatives with different costs. \\
\hline & & Too expensive recommendations aren't made. \\
\hline \multirow[t]{4}{*}{ Rational cultures } & \multirow{4}{*}{$\begin{array}{l}\text { Volunteer organizations } \\
\text { trying to work against } \\
\text { recommendations } \\
\text { (see also section } 3.2 .3 \text { ) }\end{array}$} & Inviting fixes. \\
\hline & & Thorough explanations. \\
\hline & & Dialogue with the recipient. \\
\hline & & Knowing the right people. \\
\hline \multirow{5}{*}{$\begin{array}{l}\text { Cultures where safety is } \\
\text { not the top priority }\end{array}$} & \multirow{5}{*}{\begin{tabular}{|l|} 
Resistance despite recent \\
accident vs receptive for a \\
short time after an accident. \\
Resistance due to \\
competing values. \\
(see also section 3.2.4)
\end{tabular}} & Weaker remedial actions ${ }^{1}$. \\
\hline & & Fewer remedial actions. \\
\hline & & $\begin{array}{l}\text { Adapting follow-up, explanations, and } \\
\text { arguments, }\end{array}$ \\
\hline & & Aim recommendations at another stakeholder. \\
\hline & & Publicity \\
\hline
\end{tabular}

Table 3. Resistance to change and strategies to overcome resistance to change. The first column lists the four safety culture features that characterized resistance to change. The second column exemplifies resistance to change that is characteristic of the safety culture features. The third column lists strategies for overcoming resistance to change, associated with the safety culture features.

\subsection{Resistance to change}

Four safety culture features that characterized resistance to change emerged from the analysis (see table 3). Firstly, there was a distinction between cultures that had institutionalized minimum safety standards, and those that did not. Second, some cultures were seen as rational, so that the recommendations would be implemented if only the right arguments were presented. Third, some cultures were resource-weak, so that attention had to be paid to cost-benefit. Fourth, in some cultures safety was not the top priority. Then attention had to be paid to the risk of remedial actions not being implemented. These differences in cultural characteristics highlight how the investigators perceived the essence of respective cultural type. Since cultures normally contain several overlapping subcultures and characteristics, one should always be

\footnotetext{
$1 \quad$ The more precise rationale behind this somewhat contra intuitive strategy is to adjust a recommendation to what the investigator believes to be a reasonable and acceptable recommendations in the eyes to the receiver.
} 
careful about over-generalisations when describing a culture as belonging to this or that generic type.

\subsubsection{Cultures with institutionalized minimum safety standards}

In some areas investigators could back-up demands that a safety standard dictated by rules and regulations should be followed by referring to the law. Some cultures will go above that minimum standard, and some will attempt to go below it. In for instance the maritime domain the 'flag' of a ship dictates what standards they follow, and international agreements set a common baseline. But shipping companies have the option to change flags, and this complicates the setting of rules. In other areas, investigators cannot enforce recommendations. Then the minimal safety standards are more subjective. Interestingly, due to resistance to change, these two strategies were sometimes not as different in practice as they might at first appear to be. Recipient acceptance is required even for recommendations backed up by law, if compliance cannot be monitored.

\subsubsection{Resource-weak cultures}

There were many examples of resistance due to resource-weak cultures that cannot implement everything that is good for safety.

Cost-benefit depends on the safety climate. If the safety climate is good, then cost for a one-day course in safety is easier to argue with management. A worse climate requires better arguments, such as presenting data accident data (road). Safety should not rise and decline following the economy at large in society (maritime).

Lack of money stops remedial actions. In the rail domain, the most expensive recommendation (level railway crossings) could not always be proposed since too many of them would be needed (rail, excerpt 2). In contrast, in cases where consequences are also costly, then cost of remedial actions was no problem (rail). In the work domain, an informant would think twice if the company was small, and the improvement was very expensive, since the company then might have to relocate their business (work).

\footnotetext{
Excerpt 2 (rail): "I: So you have never said that this remedial action was too expensive? This cannot be done?

$R$ : That has actually happened. It's very easy to write, take for instance accidents where a road crosses the rails, then it is very easy to write that the level crossing should be removed. To write that it should go over or under the rails. But one cannot write that in all investigations because it is impossible, economically. It can't be done, we have thousands of level crossings in Sweden."
}

Resistance due to existing budget plans. In the road domain, one informant thought that it was sometimes unpopular to go to a planner, who had already prepared the budget, and say that the money was needed for something else.

\subsubsection{Rational cultures}

In some organizations, which can be characterized as rational cultures, change was resisted if rational arguments were lacking. An example of rational cultures resisting 
change is resistance mounted by volunteer organizations. Volunteer organizations that do not want to accept a recommendation can work against it, for instance, by contacting a newspaper (road).

\subsubsection{Cultures where safety is not a top priority}

There were mixed views of resistance to change following accidents. Some investigators thought acceptance increased, while others thought resistance could be a forceful factor that acted against change even right after an accident. That is indicative of cultures that do not have safety as the top priority.

Receptive just after an accident. In the work domain, one informant thought there was no difference between organizations just after an accident - all are receptive to change after accidents (work).

Resistance despite a recent accident. Another informant disagreed, and thought that there could be resistance even after an accident. Without a person dedicated to safety, the situation would in half a year revert to where it had been before the accident and any remedial actions, regardless of threats of legal action (work). One informant in the maritime domain had experienced that affected parties sometimes wanted to edit out parts of the report if they got to read it during a review round. Although, sending it out for review could also be beneficial. In another domain, an investigator did not dare criticize management even though it would have been appropriate to do so (anonymous). In the patient safety domain, a informant mentioned that regarding a recurrent accident, the recipient had not implemented any of the recommendations from the previous investigation (patient safety, excerpt 1 ).

\section{Excerpt 1 (patient safety) "We have experienced the same accidents repeatedly} despite having suggested remedial actions after the investigation followed by the first event. When we ask the manager"what did you do about it" it turns out they have not implemented any of our previous recommendations."

Resistance due to competing values. An example from the road domain illustrated how value judgments could hinder remedial actions. The ability to move quickly on the roads was valued highly, and safety improvements that reduced movement were therefore unpopular among the construction staff. Although, the informant had also noticed that the construction staff had recently become more positive to the suggestions. In particular, since it had turned out that some safety improvements had positive effects on traffic flow.

\subsection{Strategies for overcoming resistance to change}

The investigators strategies for overcoming resistance to change (see Table 3) reflect salient features of the safety they encountered. Although other features might also play a role, our informants mostly spoke about four features that characterised the safety cultures they normally worked with or worked within. The investigators mainly talked about successful strategies to achieve change in the different cultures, but sometimes also gave examples of limitations of the strategies. 


\subsubsection{Cultures with institutionalized minimum safety standards}

Regarding cultures with institutionalized minimum safety standards, there were two main strategies to achieve change. First, to demand change based on laws, and second, to suggest changes for the recipient to consider.

Back up by law but relying on recipient acceptance. In the work and maritime domains, investigators mainly made demands backed up by law. However, many reasons and examples were given of situations where this strategy was ineffective. In the work domain it was mentioned that even if something is required, it cannot always be enforced, so that in the end, the effectiveness depends on recipient acceptance (work). As an example it was mentioned that for objects like a physical barrier on a machine, it is possible to check whether it is there, but that routines cannot be monitored for compliance at all times (work). This was mentioned also in the road domain, for changes directed at the public. The informant thought it was easier to work with rules, but that some rules nevertheless required acceptance to be effective, such as a law requiring children to wear helmets when on their bikes. If a child was found not wearing a helmet, it would be difficult to hold the parent accountable for it (road). Sometimes, only safety token could be demanded, such as a truck driver's license in the work domain - but no demands could be made of requirements for getting the license (work).

Suggesting change. In domains where changes could be demanded and backed up by law, it was common to also make suggestions (rather than requirements) without law to support them. In the work domain, suggestions were placed in a discussion section of the investigation report to differentiate them from the requirements that were presented in the 'inspection message' where changes were demanded. In the nuclear, road, aviation, and patient safety (excerpt 3) domains the informants only worked with suggestions, with no laws to back up their recommendations. Acceptance was then seen as important by many informants.

Excerpt 3 (patient safety): "I: How important is it that the addressed organization accepts the proposed remedial actions?

$R$ : It is very important. They implement the remedial actions, not us. If they do not accept them, then they will not be implemented"

\subsubsection{Resource-weak cultures}

Various decision-making practices regarding remedial actions were reported. An important decision is, of course, what the recommendations should be in the first place. In line with what we have reported elsewhere (Rollenhagen et al., 2010), as well as by Carroll (2006) the present study confirmed the observation that decisions about remedial actions are made by different stakeholders. Recommendations are often decided in a two-step process - first by the accident investigators (as a set of suggestions) and then possibly changed and formalized by managers in the receiving organizations. Analysis of cost-benefits are to various extents part of these decisions. In some interviews there were signs of moving the responsibility for cost-benefit analysis to the receiving organization. Below, we give examples of how the investigators described strategies that relate to cost-benefit, from one extreme, demanding that remedial actions are implemented regardless of cost, to a middle ground of providing 
alternatives with different costs, to another extreme of not making recommendations that are thought to be too expensive.

Demand that remedial actions are implemented regardless of cost. One informant in the maritime domain said that remedial actions were demanded regardless of whether the recipient could afford them - although an effort was made to make recommendations that were not costly. However, sometimes, smaller organizations were given more time to implement recommendations. But they were also given some restrictions regarding what work they were allowed to do before having implemented the recommendations (work, excerpt 4).

Excerpt 4 (work): "I: Cost benefit, how do you work with that balance? If you suggest something, then there can be a cost? [...]

$R$ : If you do an inspection after an accident at a small firm, maybe with just a few employees, then maybe their economy is not that strong, and they will tell you that. But we can't make demands on a lower level, just because of their economy. We are not allowed to do that, because it should not happen again. But, if there is no immediate threat (if it is, then it needs to be done immediately)... then it can be put in a plan. They can show their plan, and make a budget for the coming years. [...] This valve must be replaced now, and then you educate one at a time. And then that person must be responsible for this, until you are done. Only that person may build scaffolding until you can afford to let the others take the scaffolding course"

Leave the cost-benefit decision to the law makers. An informant in the work domain explained that cost/benefit judgments had already been made by law makers.

Recommendations that are known to be too expensive and are expected to be turned down by the recipient are nevertheless proposed. In the aviation domain, one informant stated that they sometimes made recommendations they knew would be too expensive, but they still had to make them. The informant thought it was a dilemma. On the one hand the recommendations must be affordable, but on the other hand if something keeps happening, then a repeated expensive recommendation might be reconsidered (aviation). One informant in the patient safety domain explained that suggestions were made regardless of cost, but that investigators could not demand expensive items were replaced since hospitals probably could not afford it (patient safety, see excerpt 5). If something was too expensive, for instance to rebuild a part of the hospital, then the informant knew it would not be done (patient safety), although another informant was less sure. However, if the decision maker was included in the investigation team, then too expensive suggestions might be turned down already in the investigation process (patient safety).

Excerpt 5 (patient safety): "R: I can't tell a clinic that 'you have to get a new $x$-ray machine, because the old one is too old, for 4 million Swedish krona.' It is the clinic manager who must see that 'now there has been such and such an amount of deviations on this machine, and it is 10 years old, so we have to replace it. But that decision must be taken there, and become accepted there. I can only point out that it seems dangerous, that it is inappropriate, and possibly the supervisory authority can 
point it out as well. But they can't tell the clinic to buy a new machine either, when there is no money.

I: But you wouldn't mind making a suggestion?

$R$ : We have done that many times. But it is up to the clinic to decide if they can afford it."

Give recommendations regardless of cost and leave the decision entirely to the recipient. Several informants explained that cost-benefit analyses were not made by the investigators (aviation, rail, nuclear). The recipient decision makers then were on their own in making decisions. In the road domain, there were decision makers on different levels, depending on cost. Decision makers might also decide to make improvements at some place that was riskier than the one where an accident had occurred (road). Some informants emphasized that they on the whole only made recommendations that were reasonable. But there were examples of extremely unreasonable cases, such as replacing nuclear power with wind turbines. One informant thought that everything would be implemented if it was important for safety and if there was good support from analysis (nuclear).

Put a price tag on recommendations. An informant in the patient safety domain explained that a price tag could be put on the recommendations in order to make it easier to judge the cost-benefit of the recommendations versus other needs. According to another informant, a price tag was calculated by the decision maker who decided whether the problem would be a risk they had to live with (patient safety). In the same domain, a third informant said that a cost discussion was made with the recipient (who then in turn could ask for more resources). In the rail domain, recommendations were evaluated together with those who were responsible for economy, to see what was realistic to implement in the short and in the long run. The cost calculation could be a first step, after the investigation, but before the decision was made (rail). Sometimes, cost was not an issue after all, for instance if the hazard was really high, such as a collision between trains (rail).

Propose alternatives with different costs. In the road domain smaller and less costly changes were considered before larger ones. Another informant made clear that when several recommendations were made, alternatives might have different costs. (road, excerpt 6). In the patient safety domain, both overly expensive and more reasonable suggestions were made. As an example, a routine could sometimes be suggested as an alternative to buying a new machine. If, for instance, the screen on the current machine was not good enough, a routine to print out the contents could be proposed (patient safety). Another informant thought that if recommendations were very effective but also very costly, then alternatives could be proposed until the more costly remedy could be implemented (patient safety).

Excerpt 6 (road): "I can have numerous suggestions for remedial actions, for instance 'lower the speed', or 'close a road', 'or move an entry point to the road', or similar things. Then they either implement all of them, or some of them, or maybe nothing at all. That is not our decision." 
Recommendations seen as too expensive are not made. An informant in the road domain pointed out that whole classes of recommendations were seen as too expensive. For instance, work with changing behaviour in the road domain was not seen as costeffective. In the aviation domain an informant thought that when many small factors were expensive to fix, then it would be pointless to propose fixing them. In the rail domain, demands backed up by law were made. But they also made suggestions, except when they expected the recipient to find them obviously too expensive. When giving suggestions deemed to be too expensive, investigators thought they had at least given the recipient something to think about (maritime).

It is hardly surprising that economy is a concern when remedial actions are suggested. If resources are scares, an expensive recommendation may prevent other known risks from being addressed, hence reduces the overall safety. It was interesting that investigators had a variety of approaches to cope with this problem, going from giving a broad scope of both cheap and expensive recommendations, to applying a screening procedure with the hope of finding resource effective remedial actions.

\subsubsection{Rational cultures}

One set of strategies aim at rational cultures, where the investigators think the recipients will implement remedial actions if they can be convinced this will improve safety. The strategies thus aim at convincing the recipient about the need for change.

Inviting fixes. An informant in the aviation domain emphasized that recommendations would not be implemented if the recipient did not want to do so. The informant therefore thought that recommendations must be clear and invite people to make fixes (aviation, excerpt 7). In the work domain, it was mentioned that requirements could be formulated to make the recipient think 'why haven't we thought about this?'

Excerpt 7 (aviation): "I: ... recommendations fall somewhat into writing the report, but how much time do you spend on formulating and figuring the recommendations out?

$R$ : It varies a lot. It takes quite some time, since it is important to formulate them clearly, but also so that the recipient will want to implement them. That is, since we do not have the mandate to demand "you have to do this". It is more of a recommendation, and then it is important that you will want to implement it. [...] They should simply want to do it. If I just write a lot, being all negative, then that leads nowhere. Then they will not want to do it. They will not want to take my report on board (sv "ta till sig"). So it takes a lot of time, to get it on the right level."

Thorough explanations. One informant thought that the presence of facts could make their work more acceptable - that they have examined the accident and taken pictures (road).

Dialogue with the recipient. In the work domain, one informant mentioned that an 'inspection message' demanding changes often was sent quickly, and that the report came later. The informant thought it would be better to have a dialogue about the requirements in the 'inspection message' as well as the report, rather than just sending 
over an 'inspection message.' The dialogue could elicit the recipient's viewpoints on the report and serve as follow-up of the 'inspection message' at the same time (work). In the aviation domain, recipients were involved and could give input and have opinions during the investigation work. One informant thought that dialogue could facilitate understanding, since formulations could be changed (aviation). Another informant thought that the recipient's understanding could be increased through dialogue, and also facilitate better tailoring of recommendations (nuclear, excerpt 8).

Excerpt 8 (nuclear): "Those who have conducted the investigation present the analysis and recommended remedial actions for the recipients and those affected by the investigation. Then there is a discussion before including the recommendations into the report, to hear their thoughts and comments regarding the suggestions. The idea, as I mentioned earlier, is to get the recommendations more tailored to the recipient and to give them a deeper insight into the problems. Sometimes it is also a question of explanations, to get the recipients to understand the aspects of man, technology and organization in the event."

According to one informant an advantage of a dialogue was that resistance was made clear and could be discussed (nuclear). In the aviation domain, an informant thought they could become more convincing by appearing in the organization in other contexts, with other activities, and thereby demonstrate their competence. However, one informant was opposed to the idea of dialogue about suggestions. The informant thought this would restrict their freedom to make the necessary suggestions (maritime, excerpt 9).

Excerpt 9 (maritime): "Regarding the descriptive part of the report, for instance the events, we can contact the recipient and ask for their view on what we have written. But regarding the analysis and the recommendations, we avoid that, because we want the freedom to write what we want. But there can be communication afterwards."

Informants described that recommendations were easy to accept if the recipients had already themselves come to the same conclusions about the causes of the investigation (rail).

Knowing the right people. For in-house suggestions, two informants mentioned that they could easily go and talk to people, and that this sometimes resulted in quick changes (regulations, for maritime investigations, minor issues in road traffic).

\subsubsection{Cultures where safety is not the top priority}

Reliably measuring the 'true' safety of a system is a challenging epistemological and ontological problem that is much debated in safety science. From a pragmatic perspective, the stakeholders in a system and observers outside a system usually have different beliefs and opinions about the 'level' of risk and safety that characterize the system. Such beliefs affect what people do either inside the system boundaries or from the outside. The present study found that accident investigators seek to adapt their recommendations to what they believe are the safety characteristics' of the observed 
system, i.e., to the stakeholders' beliefs and opinions. As a result, the remedial actions may vary (although not necessarily) depending on how the investigators perceive the recipient organization's safety culture. Other factors also seem to be important in judging suitable recommendations, including: external rules and regulations, the size of an organization, judgments about socio-economic factors, etc. Some examples of these factors are given below in the interview fragments. Several investigators clearly adjusted their recommendations to the perceived safety level of the recipient. They both adjusted the recommendations and their explanations, arguments and follow-up. In response to cultures where safety was not a top priority, they sometimes proposed fewer and weaker remedial actions.

Weaker remedial actions. A strategy to overcome resistance to change by the general public was to adjust to what was perceived as acceptable. As an example from the road domain, one informant described a road through a small village, where the speed should be restricted to $30 \mathrm{~km} / \mathrm{h}$ to be safe for people walking by the roadside (they would then probably survive being hit by a car). However, the informant said people would not accept driving that slowly through the whole village. Therefore, low speed would only be used where it was particularly dangerous (road). Another informant saw some occupations as more risky than others, and adjusted the remedial actions to that. As an example, if the same standards were set for small shipping vessels as for passenger ferries, then there would be no longer be any fishing vessels (maritime).

Fewer remedial actions. In the patient safety domain, two investigators thought that it would be harder to get remedial actions implemented if safety thinking was not so high on the agenda (patient safety, excerpt 10).

Excerpt 10 (patient safety): "I can imagine that the remedial actions will not be implemented in the way they claim that they will be implemented, and that they do not realize that this is important."

In the maritime domain, when the safety level was perceived as lower, one investigator refrained from suggesting voluntary remedial actions. The informant thought that in organizations that prioritize safety, suggestions are more likely to be followed (maritime). In the work domain, one informant thought that it was much easier to launch more expensive actions in an organization where safety was a top priority, (work).

Adapting follow-up, explanations, and arguments. One informant in the patient safety domain was more thorough with follow-up of implementation of recommendations where safety was seen as lacking, rather than adjusting the recommendations per se. Another informant adapted explanations of the recommendations and arguments to the safety level (patient safety).

Aim recommendations at another stakeholder. The road domain provided another example of dealing with resistance to change. After an accident with a delivery truck, the company that owned the trucks thought safety was the responsibility of the drivers and the drivers' organization. In such cases where the recipient could not be forced to 
change anything, actions could be directed at other stakeholders, such as the municipality (markings on the road for delivery trucks) or the store (but they were not terribly interested either) (road, excerpt 11).

\begin{abstract}
Excerpt 11 (road): "There was an accident in a medium size town, where a bread lorry extended its rear lift into the street - and a car ran into the extended lift. The driver got hit in the face by the lift and died. Then I recommended the company to educate their drivers, and join the quality assured transportation program. But they were not interested and assigned all responsibility to the drivers of the lorries. They have their own interest organization. But there were more remedial actions in this case. For instance, to create zones for loading and unloading in the street. That's the responsibility of the municipality. So that they can park along the street, instead of across the street as in this case."
\end{abstract}

Publicity. As one informant from the maritime domain mentioned, publicity can be a force to get suggestions accepted. If the recipient declines implementing the recommendations, then media can write about them (if they request the public documents) (maritime).

The strategy to adapt recommendations to the perceived safety of the recipient organization is a double-edged sword. On the one hand, it is rational and efficient to adapt recommendations so that the probability of their implementation is maximized. On the other hand, there is something unjust in reducing the demands to an organization just because they have not developed their safety well enough. Moreover, as it is difficult to judge safety in an objective way, there is a risk that some organizations are burdened with more extensive demands depending on subjective perceptions on a given 'safety level.'

\title{
4. Discussion
}

This study has shown that when investigators encounter resistance to change they use a number of strategies that are attuned to different safety culture features. This extends previous research, which generally has assumed that safety would increase if investigators only were given the proper methodological tools and concepts to address ever-changing causes. This issue regrettably receives scant attention from investigation manuals, and limited time is spent on it in the design of recommendations, implementation and follow-through (Lundberg et al., 2009; Rollenhagen et al., 2010).

Traditional accident investigation methods (e.g. Lundberg et al., 2009) goes directly from the design and suggestion of remedial actions to the step of implementation and to the follow-up, even though investigators rarely are involved in the implementation, and even though the follow-up rarely is done in practice. This study argues that it is important to look closer at the fourth step, how to implement the remedial actions. Depending on the effectiveness of the strategy used, the path may go to 'remedial action implemented' or 'remedial action resisted.' 


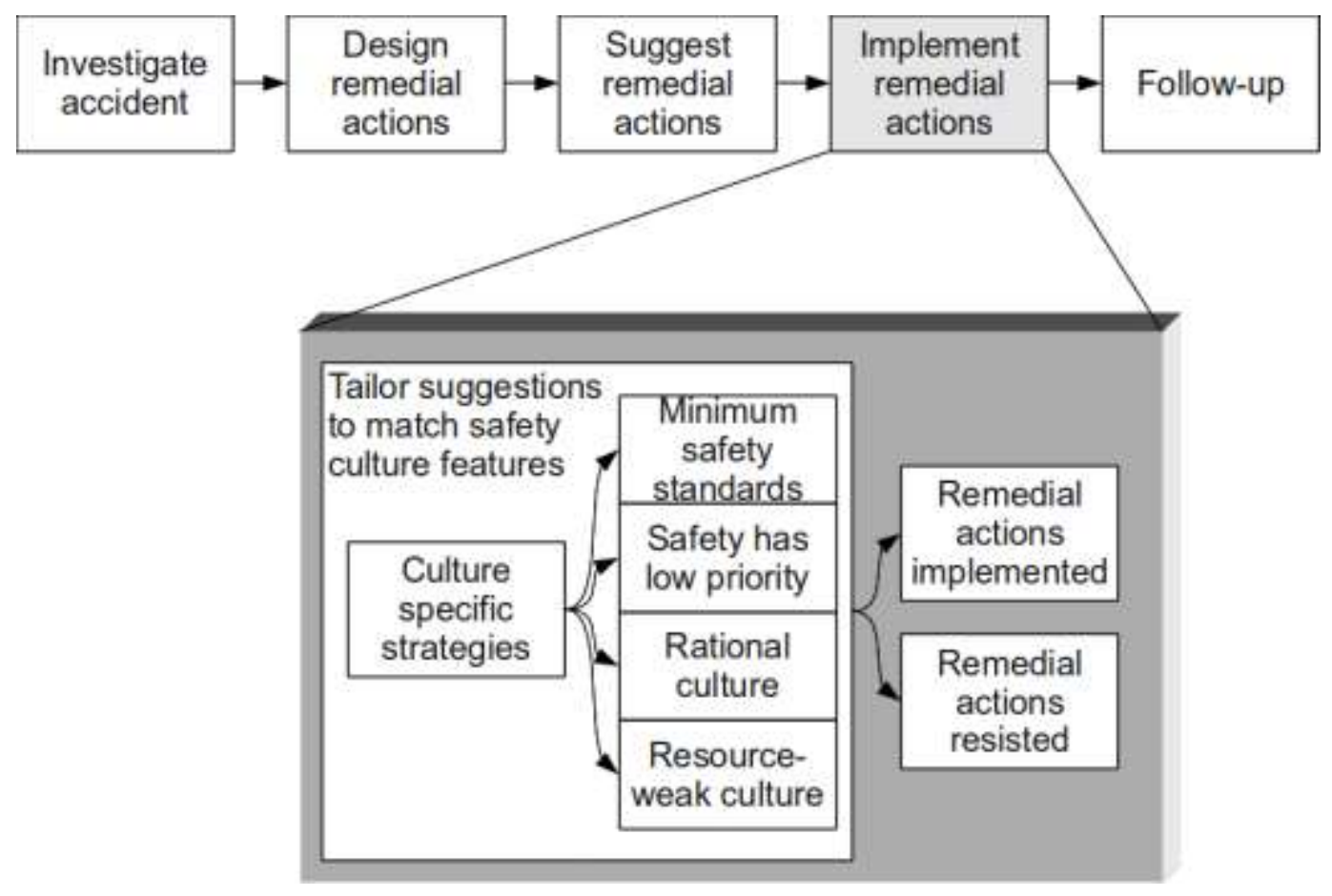

Figure 1. Strategies for overcoming resistance to change.

In this fourth step (cf., Figure 1), four safety cultural features can affect how successful the implementation of remedial actions may be. A culture of minimum safety standards may prevent remedial actions from being forced on the recipient. A culture where safety is not given priority may resist remedial actions that do not match the recipient's overarching goals. A rational culture will resist changes if the recipient is not convinced it is necessary to make them (even if safety is prioritized). And finally, even if the recipient is convinced about the need for change, and prioritizes change, lack of resources may prevent an implementation.

Our findings regarding resistance to change and strategies for achieving change can also be described in terms of forces in studies of safety (Figure 2). The investigators attempt to add to the current safety 'level', e.g. current rules, procedures, hardware for safety (L1, Figure 2), reaching a new state with increased safety if proposed remedial actions are implemented (L2, Figure 2). Usually this means additional rules, or safety equipment, although it could also mean that some inappropriate rule or safety equipment would be removed. The figure illustrates that although we discuss each strategy and resisting culture separately, they can to various extents co-exist in organizations. The top of the figure illustrates constraining forces (resistance), the middle part the strategies for change that the investigators talked about, to create a willingness to change. Finally, for completeness, the figure exemplifies forces that prevent further safety degradation. Those however are not the focus of the current study. 


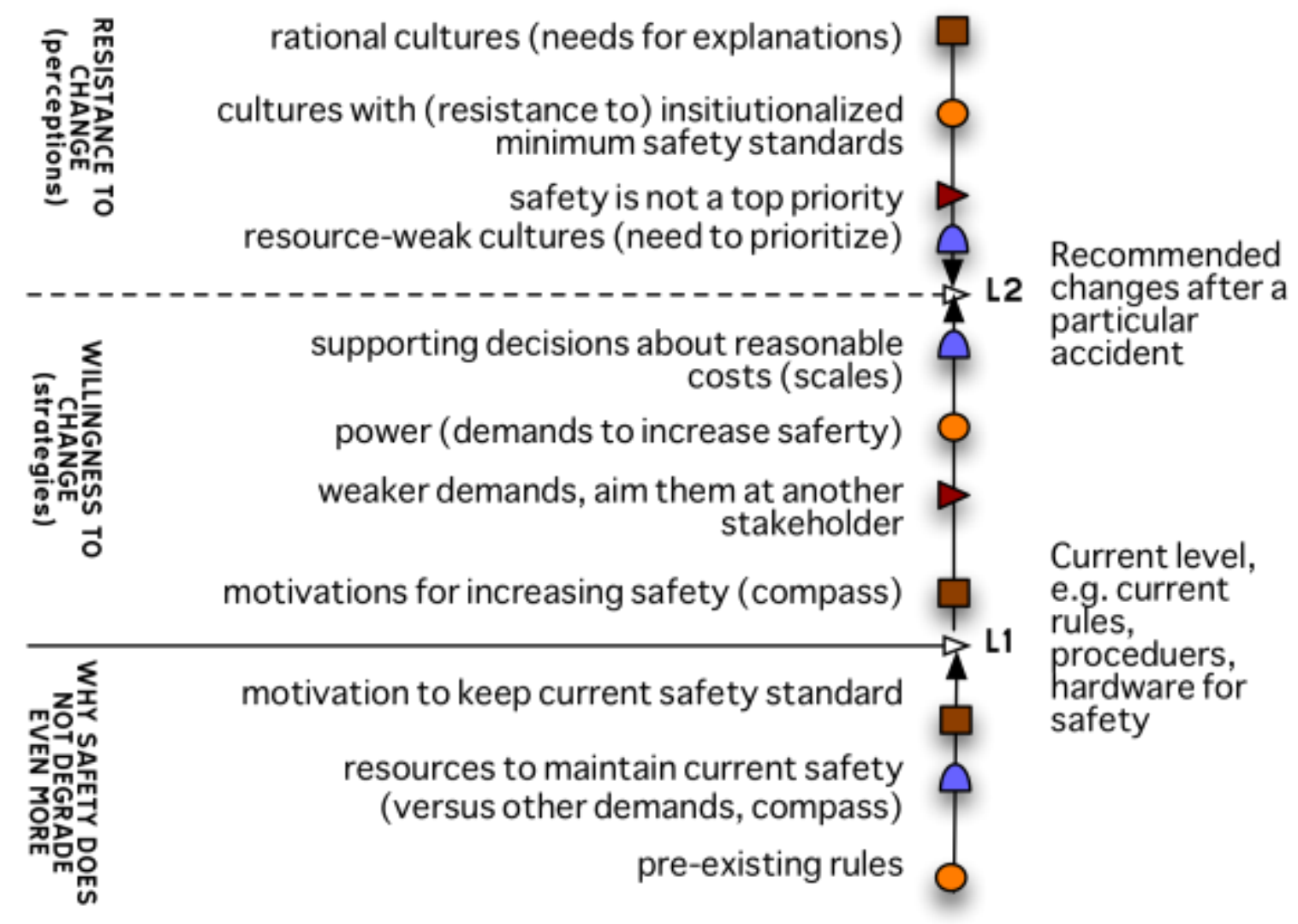

Figure 2. Resistance to change as forces. L1 denotes the current safety level, as e.g. current rules, procedures and hardware for safety. L2 denotes a desired, higher safety level, that also includes recommended changes. The figure illustrates the four safety culture features in our study as forces, e.g. rational cultures (square), cultures with (resistance to) institutionalized minimum safety standards (circle), cultures where safety is not a top priority (triangle), and resource-weak cultures (rounded square). The figure firstly illustrates the culture characteristics as forces towards L1, that is reasons why safety does not degrade even more. Secondly, it illustrates the forces as a positive drive towards L2, that is towards change (enabled by strategies to overcome resistance to change). Finally, it illustrates forces from L2 towards L1, that is forces of resistance to change.

It should be emphasised that the "safety level" is not fixed. This is exemplified in Figure 3 , using two examples of forces from our study to illustrate that some safety improvements only work when attitudes towards safety are stronger. 


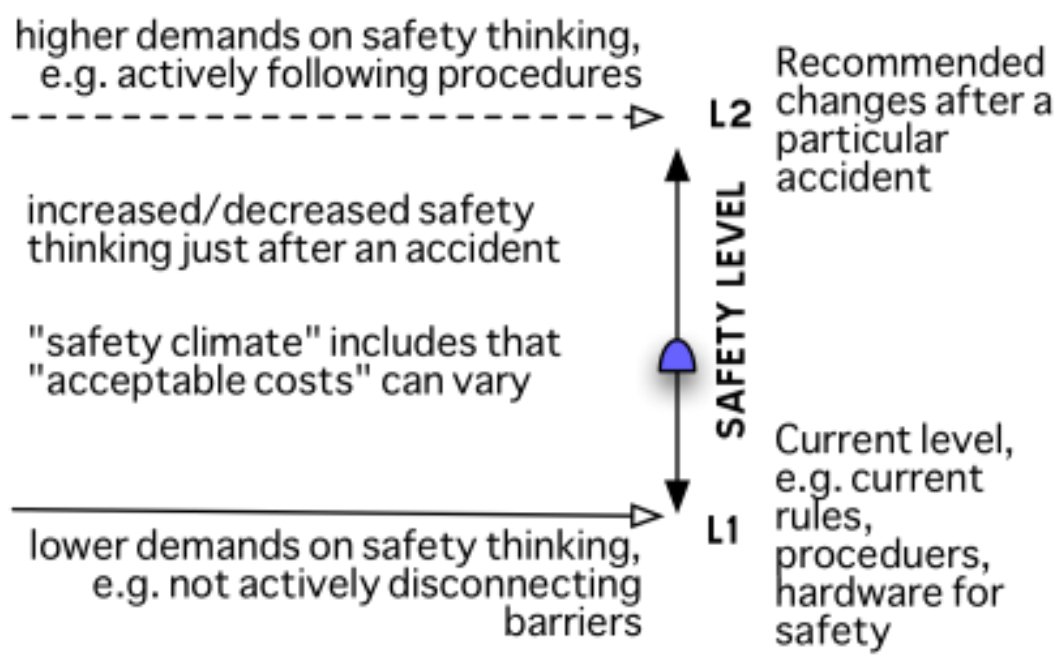

Figure 3. Example of forces involved in variation of safety levels and interactions with recommended changes. At level L1, the demands for safety thinking that

recommendations depend on are lower than at level L2. For instance, if safety thinking increases just after an accident, to level L2 where people actively follows procedures, this recommendation will no longer work if the system later reverts to level L1, where demands are lower (e.g. not actively disconnecting barriers). "acceptable costs" is another variable that can change with the safety climate, affecting to what cost safety can be realized, with more expensive recommendations being accepted at level L2.

It is worth emphasizing that the "forces" towards change do not simply occur, they rely on active work by the investigator and recipient. Strategies to overcome resistance to change have been described in the preceding sections, and are also summarised in Table 4. As shown in the table, the strategies can also be characterized in terms of ethics (duty, trading-off, orienting) and power. Strategies that mainly rely on orienting are those that aim at 'rational cultures.' Strategies that rely on trade-off aim at resource-weak cultures. Strategies for institutionalising safety standards can also appeal to a sense of duty. Finally, when it comes to cultures where safety is not a top priority, one strategy is to use trade-offs to make recommendations less demanding, or to rely on power.

Regarding power, Table 4 indicates what strategies draw on the most obvious use of power, that of making someone else do what they might otherwise not have done. This is the first of three kinds described by Antonsen (2009). It relies on coerciveness, but also on alliances and networks (e.g. strategy 13). It should be noted that the second aspect of power, that of setting the agenda, to various extents is exerted in the trade-off strategies. For instance, presenting fewer recommendations (strategy 15) is a different way of setting the agenda, arguably with the investigator exerting more power, than to present different alternatives with costs attached (strategy, 8). It should also be noted that the investigators do not exert power unilaterally. Through their strategies they negotiate their findings of change needs with the agenda of the recipient. This agenda setting, the influence of values of the recipient on the investigator, corresponds to the third aspect of power.

Considering previous research on change in high-reliability organizations, resistance to 
change can be necessary to maintain practices that time and experience have proven to be safe. Especially in those situations, it appears that strategies that include the 'orienting' characteristic are appropriate, to ensure that changes are well-grounded. A high-reliability organization where safety is no longer a top priority though would be particularly problematic, since strategies then would have to include other characteristics as well. If the 'compass' in the recipient HRO no longer points towards safety, it is likely that safety will degrade (i.e. it will no longer be an HRO). An indicator of such degradation could be that strategies for change included other characteristics than being 'orienting.'

Resource-weak cultures present a different challenge, that of balancing safety needs based on investigations with other (costly) safety concerns. It then becomes important to make trade-off in terms of different options clear.

Regarding cultures with institutional minimum safety standards, it appears that when they are unable to add new standards, or monitor and enforce existing standards, then the situation becomes more complex, and other cultural characteristics needs to be taken into account. It should therefore be emphasised that strategies for change are relevant also for cultures with minimum safety standards. Especially for high-reliability organizations, all demands need to be thoroughly explained, even if they are backed up by rules or law.

\begin{tabular}{|c|c|c|c|}
\hline \# & Strategy / Rule-of-thumb & \begin{tabular}{l|l} 
Po & Tr \\
we & ad \\
$r$ & e- \\
& off
\end{tabular} & \begin{tabular}{|l|l} 
Du & Ori \\
ty & ent \\
& ing
\end{tabular} \\
\hline & Cultures with institutionalized minimum safety standards & & \\
\hline 1 & Back up by law & & \\
\hline \multirow[t]{2}{*}{2} & Suggesting change & & \\
\hline & Resource-weak cultures & & \\
\hline 3 & Demand that remedial actions are implemented regardless of cost & & \\
\hline 4 & Leave the cost-benefit decision to the law makers. & & \\
\hline 5 & $\begin{array}{l}\text { Recommendations that are known to be too expensive and are expected to be } \\
\text { turned down by the recipient are nevertheless proposed }\end{array}$ & & \\
\hline 6 & $\begin{array}{l}\text { Give recommendations regardless of cost and leave decision entirely to the } \\
\text { recipient }\end{array}$ & & \\
\hline 7 & Set a price tag on recommendations. & & \\
\hline 8 & Present alternatives with different costs. & & \\
\hline \multirow[t]{2}{*}{9} & Too expensive recommendations aren't made & & \\
\hline & Rational cultures & & \\
\hline 10 & Inviting fixes & & \\
\hline 11 & Thorough explanations & & \\
\hline 12 & Dialogue with the recipient & & \\
\hline \multirow[t]{2}{*}{13} & Knowing the right people & & \\
\hline & Cultures where safety is not the top priority & & \\
\hline 14 & Weaker remedial actions & & \\
\hline 15 & Fewer remedial actions & & \\
\hline 16 & Adapting follow-up, explanations, and arguments. & & \\
\hline
\end{tabular}


17 Aim recommendations at another stakeholder

18 Publicity

Table 4. Rules-of-thumb versus safety culture. Black marks indicate the characteristics power, trade-off, duty and orienting that the strateiges draw on.

It should be noted that a limitation of this study is that we have not attempted to find out how common or wide spread the strategies are. It is also likely that including other investigators could result in more or different strategies, although our investigation does cover a sample across several domains.

Regarding broader studies on organizational change, we found similar characteristics to studies on change, e.g. context factors such as being informed (e.g. Strategies 7,8, 11,12) and participation in change (in particular strategy 12, Table 4) (Cooper, 1998; Wanberg and Banas, 2000). However, we did not find (or did not focus our interviews on) perceptions about individual recipient characteristics such as self-esteem, optimism, self-esteem (Wanberg and Banas, 2000). Furthermore, managerial dispositional traits found in previous research could also be expected to influence how remedial actions are received (Judge et al., 1999), an aspect this study has not focussed on.

\section{Conclusions}

Several strategies, or rules-of-thumb, for dealing with resistance to change were presented, all of which were related to safety culture features (Figure 2, Table 4). The strategies are part of a phase of accident investigation, which has previously received scant attention, namely the activity of implementing strategies for overcoming resistance to change (Figure 1).

This study argues that there is a need for more effective methods to overcome resistance to change, in addition to a need for better methods to explain accidents. Overcoming resistance to change is clearly a central aspect of investigation, regardless of the type of safety culture. In conclusion, the strategies for overcoming resistance to change appear to be at least as important to avoid future negative events as the strategies for finding and analysing causes. It might be a benefit for accident investigation agencies to include an explicit section on their specific view on these strategies in their manuals and policy documents. Practical education of investigators could also benefit from explicitly dealing with these issues.

It is also important to examine how the strategies, alone or in combination, work in practice, especially when cultures exhibit multiple features. Another important topic is to find more effective strategies.

There are also challenges related to organizational change interacting with safety motivated change, for instance how the safety culture characteristics found here (as perceived by the investigators) interact with traditional notions of organizational change by recipients?

\section{Acknowledgements}


This research was sponsored by the Swedish Civil Contingencies Agency, through the project 'Assumptions on accidents - generalisability for practical investigation work in different domains.'

\section{References}

Antonsen, S., 2009. Safety culture and the issue of power. Saf. Sci. 47 (2), 183-191.

Ashforth, B.E., Lee, R.T., 1990. Defensive behavior in organizations: A preliminary model. Human Relations 43 (7), 621-648.

Carroll, G.R., Teo, A.C., 1996. Creative self-destruction among organizations: An empirical study of technical innovation and organizational failure in the american automobile industry, 1885-1981. Ind. Corp. Change 5 (2), 619-644.

Carroll, J.S., 2006. Naturalistic decision making and organizational learning in nuclear power plants: Negotiating meaning between managers and problem investigation teams. Organization Studies 27 (7), 1037-1057.

Choudhry, R., Fang, D., Mohamed, S., 2007. The nature of safety culture: A survey of the state-of-the-art. Saf. Sci. 45 (10), 993-1012.

Coch, L., French, J.R.P., Jr. , 1948. Overcoming resistance to change. Human Relations 1, 512-532.

Cooper, D., 1998. Improving safety culture: A practical guide. Applied Behavioural Sciences Hull, UK.

Dent, E.B., Galloway Goldberg, S., 1999. Challenging "resistance to change". J. Appl. Behav. Sci. 35 (1), 25-41

Dutton, J.E., Ashford, S.J., 1993. Selling issues to top management. Acad. Manage. Rev. 18 (3), 397-428.

Dutton, J.E., Ashford, S.J., O'neill, R.M., Hayes, E., Wierba, E.E., 1997. Reading the wind: How middle managers assess the context for selling issues to top managers. Strategic Management Journal 18 (5), 407-423.

Elvik, R., 2010. Why some road safety problems are more difficult to solve than others. Accid. Anal. Prev. 42 (4), 1089-1096.

Factor, R., Mahalel, D., Yair, G., 2007. The social accident: A theoretical model and a research agenda for studying the influence of social and cultural characteristics on motor vehicle accidents. Accid. Anal. Prev. 39 (5), 914-921.

Gordon, J.E., 1949. The epidemiology of accidents. Am. J. Public Health 39 (4), 504-515.

Grote, G., 2008. Diagnosis of safety culture: A replication and extension towards assessing. Saf. Sci. 46 (3), 450-460.

Guldenmund, F., 2000. The nature of safety culture: A review of theory and research. Saf. Sci. 34 (1), 215-257.

Hansson, S., 2007. Ethics and radiation protection. JRP 27, 147.

Heinrich, H.W., 1934. The accident sequence. Safety Talks (November 30th), 1-5.

Herrera, I.A., Nordskag, A.O., Myhre, G., Halvorsen, K., 2009. Aviation safety and maintenance under major organizational changes, investigating non-existing accidents. Accid. Anal. Prev. 41 (6), 1155-1163.

Holling, C., 1973. Resilience and stability of ecological systems. Annu. Rev. Ecol. Syst. 4, 1-23.

Hollnagel, E., 2004. Barriers and accident prevention. Ashgate, Burlington, VT

Hollnagel, E., 2009. The four cornerstones of resilience engineering. In: Nemeth, C., Hollnagel, E., Dekker, S. eds. Resilience engineering perspectives, vol. 2, 
preparation and restoration. Ashgate, Farnham, UK, pp. 117-133.

Jansen, K., 2000. The emerging dynamics of change. Resistance, readiness, and momentum. Human Resource Planning 23 (2), 53-55.

Judge, T.A., Thoresen, C.J., Pucik, V., Welbourne, T.M., 1999. Managerial coping with organizational change: A dispositional perspective. J. Appl. Psychol. 84 (1), 107122.

KjelléN, U., 2000. Prevention of accidents through experience feedback. Taylor \& Francis, London.

Knox, N.W., Eicher, R.W., 1992. Mort user's manual for use with the management oversight and risk tree analytical logic diagram. System Safety Development Center, Idaho National Engineering Laboratory Idaho Falls, Idaho.

Korolija, N., Lundberg, J., 2010. Speaking of human factors: Emergent meanings in interviews with professional accident investigators. Saf. Sci. 48 (2), 157-165.

Lau, C.M., Woodman, R.W., 1995. Understanding organizational change: A schematic perspective. Acad. Manage. J. 38 (2), 537-544.

Lehto, M., Salvendy, G., 1991. Models of accident causation and their application: Review and reappraisal. J. Eng. Technol. Manage. 8 (2), 173-205.

Lewin, K., 1947. Frontiers in group dynamics. Human Relations 1 (2), 143.

Lofquist, E.A., Greve, A., Olsson, U.H., 2011. Modeling attitudes and perceptions as predictors for changing safety margins during organizational change. Saf. Sci. 49 (3), 531-541.

Lundberg, J., Johansson, B., 2006. Resilience, stability and requisite interpretation in accident investigations. In: Proceedings of the 2nd Symposium on Resilience Engineering, Juan-les-Pins, France, pp. 191-198.

Lundberg, J., Rollenhagen, C., Hollnagel, E., 2009. What-you-look-for-is-what-you-find the consequences of underlying accident models in eight accident investigation manuals. Saf. Sci. 47 (10), 1297-1311.

Lundberg, J., Rollenhagen, C., Hollnagel, E., 2010. What you find is not always what you fix--how other aspects than causes of accidents decide recommendations for remedial actions. Accid. Anal. Prev. 42 (6), 2132-2139.

Mabin, V.J., Forgeson, S., Green , L., 2001. Harnessing resistance: Using the theory of constraints to assist change management. Journal of European Industrial Training 25 (2/3/4), 168-191.

Miles, B., Matthew, Huberman, M., A, 1994. Qualitative data analysis: An expanded sourcebook. Sage, Thousand Oaks, CA.

O'hare, D., 2000. The 'wheel of misfortune': A taxonomic approach to human factors in accident investigation and analysis in aviation and other complex systems. Ergo 43 (12), 2001-2019.

Paulino, V.D.S., 2009. Organizational change in risky environments: Space activities. Journal of Organizational Change Management 22 (3), 257-274.

Piderit, S.K., 2000. Rethinking resistance and recognizing ambivalence: A multidimensional view of attitudes toward an organizational change. The Academy of Management Review 25 (4), 783-794.

Rasmussen, J., 1997. Risk management in a dynamic society: A modelling problem. Saf. Sci. 27 (2-3), 183-213.

Rollenhagen, C., Westerlund, J., Lundberg, J., Hollnagel, E., 2010. The context and habits of accident investigation practices: A study of 108 swedish investigators. Saf. Sci. 
48 (7), 859-867.

Santos-Reyes, J., Beard, A.N., 2009. A systemic analysis of the edge hill railway accident. Accid. Anal. Prev. 41 (6), 1133-1144.

Schwarz, G.M., Shulman, A.D., 2007. The patterning of limited structural change. Journal of Organizational Change Management 20 (6), 829-846.

Singh, J.V., House, R.J., Tucker, D.J., 1986. Organizational change and organizational mortality. Adm. Sci. Q. 31 (4), 587-611.

Svenson, 0., 1991. The accident evolution and barrier function (aeb) model applied to incident analysis in the processing industries. Risk Anal. 11 (3), 499-507.

Tichy, N.M., 1983. Managing strategic change: Technical, political, and cultural dynamics. Wiley, New York.

Tveiten, C.K., Forseth, U., Rosness, R., 2006. Conflict, alienation and human reliability proceedings of the european safety and reliability conf. Guedes Soares \& Zio (eds), Taylor \& Francis Group, London, ESREL 2006, Estoril, 18-22 September, pp. 451455.

Wanberg, C.R., Banas, J.T., 2000. Predictors and outcomes of openness to changes in a reorganizing workplace. J. Appl. Psychol. 85 (1), 132-142. 